University of South Florida

DIGITAL COMMONS

Digital Commons @ University of

@ UNIVERSITY OF SOUTH FLORIDA

South Florida

QMaSC: A Handbook for Directors of

Quantitative and Mathematics Support Centers

USF Libraries

$1-1-2016$

\title{
17. Reporting Assessment Findings to External Audiences
}

Rachel M. Dunwell

Rhodes College

Grace Coulombe

Bates College

Michael E. Schuckers

St. Lawrence University

Follow this and additional works at: https://digitalcommons.usf.edu/qmasc_handbook

\section{Recommended Citation}

Rachel M. Dunwell, Grace Coulombe, Michael E. Schuckers (2016), "Reporting Assessment Findings to External Audiences", http://dx.doi.org/10.5038/9780977674435.ch17 in G. Coulombe, M. O'Neill, M. Schuckers (Eds.) A Handbook for Directors of Quantitative and Mathematical Support Centers, Neck Quill Press, http://scholarcommons.usf.edu/qmasc_handbook.

This Center Assessment is brought to you for free and open access by the USF Libraries at Digital Commons @ University of South Florida. It has been accepted for inclusion in QMaSC: A Handbook for Directors of Quantitative and Mathematics Support Centers by an authorized administrator of Digital Commons @ University of South Florida. For more information, please contact digitalcommons@usf.edu. 


\section{Reporting Assessment Findings to External Audiences}

(c) Rachel M. Dunwell, Grace Coulombe, Michael E. Schuckers, Rhodes College, Bates College, St. Lawrence University

吅

\section{Introduction}

Appropriate assessment of the performance of a QMaSC is an important task. The presentation of assessment results to external audiences is one job that QMaSC directors may be required to perform. Here we will refer to any group outside the QMaSC staff as an external audience. The key to good communication of these results is to understand the purpose for which the audience will use an assessment report. One of the most demanding audiences for an assessment of a QMaSC is an accreditation body. Because an evaluation might be likely to occur during the parent institution's accreditation review (AR), this chapter will address the expectations of a typical accreditation body. While our emphasis in this chapter is on the rigorous endeavor of reporting for accreditation bodies, the general ideas and principles will apply to other external audiences.

Not every review of a QMaSC will be as extensive as that done by an accreditation body. However, the various functions of the QMaSC should be assessed regularly. Included in such a review should be assessments of the QMaSC's performance in terms of the quantity and quality of interactions; a catalog of center accomplishments and additional services such as workshops or special projects that arise between reviews; and appropriate summaries regarding the performance of the staff as a whole as well as individual staff members. It is typical for a QMaSC to create a

Suggested Citation: Rachel M. Dunwell, Grace Coulombe, Michael E. Schuckers (2016), "Reporting Assessment Findings to External Audiences", http://dx.doi.org/10.5038/9780977674435.ch17 in G. Coulombe, M. O'Neill, M. Schuckers (Eds.) A Handbook for Directors of Quantitative and Mathematical Support Centers, Neck Quill Press, http://scholarcommons.usf .edu/qmasc_handbook.

This material is based upon work supported, in part, by the National Science Foundation under Grant DUE1255945. Any opinions, findings, and conclusions or recommendations expressed in this material are those of the author(s) and do not necessarily reflect the views of the National Science Foundation 
set of yearly goals and objectives and then assess which of these are met during the annual review process. Depending upon the reporting structure at a given institution, assessment results may be presented to an advisory board or academic dean in brief at the end of each semester, followed by a more extensive annual review at the close of each academic year.

Accreditation for an institution of higher education is conducted by one of six regional bodies (see [1] for a more complete description of accreditation in the U.S.). Each body has its own set of standards. While some variation exists in the way that these bodies view academic support centers, such differences exist at the micro level. Appendix A includes links to the web pages for these bodies. The requirements of all bodies are satisfied by a set of documents that includes the following:

- a mission statement for the center and a description of how this mission supports that of the parent institution,

- a breakdown of the QMaSC mission into a set of specific objectives,

- a detailed description of how each objective will be or has been assessed,

- a description of how assessment results are or will be converted into action (often called "closing the loop"),

- a schedule for the assessment of each objective,

- a set of reports for every assessment exercise that has been conducted (these are often called tracking reports),

- a full review of the QMaSC after every planned assessment exercise has been conducted,

- a set of annual reports showing how the assessment is integrated into the decision-making process of the QMaSC, and

- a narrative explaining how the results of the QMaSC's assessment have informed wider decisions made by the parent institution.

Such a set of documents would, for example, satisfy the Southern Association of Colleges and Schools Comprehensive Standard for Academic and Student Support Services (see page 51 of [2]), it also matches the "Developed" or "Highly Developed" descriptions in the relevant sections of rubrics used by visiting teams from the Western Association of Schools and College ([3]).

The standards of the accrediting bodies are written with the intention that they can be satisfied only if best assessment practices have been followed consistently over an extended period of time. There are many resources to assist someone who wants to learn about these practices, two of which include: Assessment Clear and Simple: A Practical Guide for Institutions, Departments, and General Education [4] and Assessing Student Learning: a common sense guide [5]. Workshops suitable for directors of QMaSCs are held regularly by the accrediting bodies and are advertised on their websites. The people working at the parent institution who are tasked with coordinating the institution's accreditation process will be the most valuable source of help; in fact, it is essential for 
the director to work with this group. This group may be identified as the Accreditation Liaison, Institutional Effectiveness, Institutional Research, or by a similar name. In this document, such a group will be identified as the Accreditation Liaison.

The rest of this chapter gives more detailed advice on each of the parts of the accreditation documentation described above. While not every QMaSC will undergo a formal review as part of an accreditation process, the information that follows is still wholly relevant to performing any external review process as well as the production of the subsequent report.

\section{Mission Statement}

An important part of documentation for the accreditation body is the mission statement of the center. These statements help guide the leadership of the center in steering long-term decision making. Typically an institution will have a hierarchical structure of missions and strategies for attaining the mission. The accrediting body will check every level of this hierarchy for compatibility to determine if all constituent parts of the institution work to support this mission. Crafting a mission statement for a QMaSC is complicated by the fact that the center services are a vital component of more than one of the institution's strategies. In particular, it is common for QMaSC services to support:

- the institution's general education curriculum,

- the learning outcomes for the academic program of one or more departments,

- the institution's student support services,

- the institution's experiential learning outcomes (the work of QMaSC student staff may serve as the basis of experiential learning), and

- the pedagogical initiatives of individual faculty and/or of academic departments (e.g., by assigning tutors to work with groups of students, a faculty member may be able to assign more challenging projects).

Therefore, the mission statement for the QMaSC should reflect the full range of its activities. By working with other members of the institutional administration, directors can develop a mission statement appropriate for their institutional culture. In the case of an AR, the QMaSC director should work with the institution's accreditation committee to discuss exactly how the center supports the mission of the parent institution and determine the most appropriate way of documenting this for the relevant accrediting body. One way of recording a mission statement and linking this to a wider mission is to write a document called an assessment plan. An adaptation of the template used at Rhodes College for its assessment plans is provided in Appendix B. Chapter 2 of [4] also details how assessment works at the institutional level and provides QMaSC directors with insight into the world of the Accreditation Liaison. 


\section{Setting Goals for Fulfilling a Mission}

One method for meeting the QMaSC mission is to establish a regular plan, which is most often accomplished by developing goals and objectives alignment with each element of the mission. Each goal must be specific enough to allow for the identification and implementation of the means of measuring its attainment. Appendix B includes a sample assessment plan template, designed to document the statement and measurement of achievement for each goal as stated in the QMaSC mission. Thus, if every goal is attained, the QMaSC has fulfilled its mission. Chapters 1 of [4] and 8 of [5] offer advice on developing goals. Appendix A of [4] includes a template for a "curriculum map" which may be used to verify that the goals relate directly to the mission and are designed to allow for a measure for attainment.

One difficulty that is particularly acute for QMaSCs is the temptation to phrase every goal in terms of improvement. Certain benchmarks should measure improvement, but it is not necessary for them all to specify this criterion. It is natural for an academic support service to have goals that start "Students attending the support sessions regularly will improve their ability to ...." What makes such goals problematic is the need for a baseline from which to measure the improvement. Without such a baseline, the goal cannot be assessed. Every goal that concerns improvement should be weighed against a goal that specifies a standard for students who interact with the QMaSC.

\section{Assessment}

For each objective itemized by the QMaSC leadership, a method must be developed for determining whether or not the center has achieved the goal. The accrediting body requires detailed descriptions of these methods and an explanation of how each assessment tool was used. Assessment is a process through which missions are fulfilled, so accrediting bodies take a dim view of data being collected and analyzed but not converted into action. They seek evidence to verify "how the loop is closed" for each individual assessment exercise. Each assessment exercise should gather a sufficient amount of data for conclusions to be drawn while allowing for the possibility of translating these conclusions into action items. Appendix B provides a sample assessment plan template for documenting such methods and anticipated actions.

Gathering such data is no simple task. Doing so in a way that facilitates converting conclusions into action is even more challenging. This process is described in depth in chapters 9 and 10 of [5] and is the subject of sessions at most assessment workshops. Forethought and planning are required for any sort of assessment. For example, suppose a QMaSC identifies as one of its goals, "Students who regularly attend sessions at the center will be able to undertake successfully the basic calculations of their courses." Possible measures might include the following: 
- asking faculty members to assess their students' competency in basic calculations by examining a selected question from one of their exams and providing student scores on that question to the QMaSC director,

- surveying students by asking them to rate their competency on a specific question or set of questions,

- asking faculty members to assign an extra credit review homework containing questions on basic calculation (it may be necessary for QMaSC staff to grade this assignment), and

- asking QMaSC staff to rate the competency of student visitors in answering questions that require basic calculations.

It is hard to conclude reliably from data derived from any one of the above metrics either that "students can successfully undertake basic calculations" or that "students cannot successfully undertake basic calculations." This is because there are multiple circumstances in which students could score high on a single measure (only one of which is that they have basic calculation skills) and many more circumstances in which they would gain a low score (only one of which is that they do not possess basic calculation skills). Suppose, for example, all the students who attended multiple sessions in the QMaSC had good scores on the exam question selected and assessed by their teachers. The circumstances that would give rise to this data might include the following:

- the question was one that could be answered using skills other than calculation,

- the question was inadvertently answered in a review session before the exam, and

- the question could be answered using only one calculation skill that is more elementary than most other basic calculations in the course.

The circumstances in which students score high on the specified exam question, rate their own abilities highly, and in which those working in the center rate the students' abilities highly, are limited, however, to students' having the ability to perform basic calculations. This suggests that perhaps more than one measure might best be applied to assess the attainment of certain goals.

A set of measures that allows a reliable conclusion to be drawn is not necessarily an adequate basis on which to act. In the case of the objective used in the example above, it would be unwise to act in any way without establishing the extent to which students possessed the relevant calculation skills prior to the start of the course, possibly using a pre-test. If it is found that students possess the desired skills prior to the start of the course, then the action must be to change the goal. If, in anticipation of this, the plan was to raise the minimum standard in the goal so that it becomes "Students who regularly attend sessions in the center will be able to successfully undertake all the basic calculations for their course and several of the more advanced calculations," then it would be sensible to collect data on students' ability to perform calculations that faculty judge to be "more advanced" (this would include collecting relevant pre-test data). If, however, the intended action is to change the instructions for QMaSC workers to focus on the concepts involved in calculations rather than the mechanisms (or vice versa), then additional data is needed regarding the areas on 
which tutors focus when working with students calculations. In short, the loop should not only be closed after the event, but it should be designed from the outset to close.

The question of whether students improve as a result of visiting the center is fraught with challenges. Unfortunately, it is not enough simply to compare the performance of QMaSC visitors with those enrolled in the same courses who do not visit the center. The issue of center visitation may not be the sole contributing factor in determining the difference in performance for these groups. For example, students who visit the QMaSC may be more motivated to do well in their courses, whereas some students might perform well in the course regardless of whether or not they use center resources. Though difficult to implement, the approach known as student matching may be used to assess the effectiveness of student visitation to the center on course performance. In particular, one can compare every student who visits the center with one or more students in the same course who have similar characteristics (SAT scores, high school GPA, class year, etc) but who do not choose to do so. Alternatively, a more complicated methodology, requiring the consultation of a statistician, involves using data from every student in a particular course to build a statistical regression model, which accounts for the possible confounding factors with terms in the regression model. Such a model would include an indicator variable to address whether or not the student used QMaSC services.

Lastly, the assessment of learning outcomes may not be appropriate, especially in the case of those students who use services only once or twice. Consequently, a director might choose to assess the effectiveness of certain services by considering qualitative reports by students regarding their experiences, counting the proportion of repeat visitors, or other approaches that use feedback and data that can be easily acquired.

\section{Documenting Assessment}

Whenever a goal is assessed, the process should be formally documented. There are several templates publicly available for creating this kind of documentation, also known as a tracking report. Some institutions have a template specific to that institution, if so, the Accreditation Liaison will have a copy on file. Appendix C contains a tracking report template adapted from the template found on page 32 of [6]. In addition to assessing the degree to which the QMaSC attains its goals, it is also important to assess the suitability of facilities (including physical space) and resources used by the center. These assessment exercises should also be documented with a tracking report.

\section{Scheduling Assessment}

For assessment to be effective - i.e., resulting in positive change - it needs to be conducted with care and sufficient time for thorough reflection. A well-done assessment is a rigorous and time-consuming process, especially in the case of an accreditation. As such, it is not unreasonable to complete only one assessment exercise per semester or per year. Accrediting bodies will expect to see a detailed schedule of assessment that gives a timeline for the assessment of every goal over 
a multi-year span. Many publicly available templates exist for such schedules. The assessment of facilities and resources should also be included in this schedule. A sample of how the timeline might be incorporated into the assessment plan is provided in the template found in Appendix B. As with tracking reports, some institutions have their own assessment schedule template. If so, the Accreditation Liaison will have a copy on file.

\section{Review of the QMASC}

After a full cycle of assessment exercises has been completed, i.e., when every goal has been measured once, the QMaSC will possess a rich set of data upon which to draw. These data can be useful for and can provide a great deal of insight into the operation of the QMaSC. As with any data analysis, it is important to recognize that any conclusions that are drawn by center leadership as well as individuals outside of the center are only as good as the data collection and analysis methodology. Consequently, it is worth reiterating that a good deal of time should be spent at the beginning of the assessment process thinking about the type of data that should be collected.

Accrediting bodies will look to see that the assessment data is fully utilized. Only after a full assessment cycle is it possible to determine whether or not the center is productive, fulfilling its mission and supporting the mission of the parent institution. Appropriate actions should be devised based upon the external review, and the associated results should be communicated to interested parties. Tracking reports are a suitable way to document these reviews. Upon completion of an assessment cycle, the mission statement should be revisited and, if necessary, revised when previous stated objectives are deemed no longer suitable. When such changes are made, the feasibility of the assessment schedule should also be examined and appropriately altered to reflect any changes in the mission. This review and the implementation of any changes should also be documented.

The ways in which the center functions and the facilities it uses are also subject to review. A review of center operations should involve QMaSC staff and the faculty members whose students use the center. Making changes to QMaSC operations requires cooperation and tact. A review of the facilities should include not only the space it occupies but also the resources (including financial) that are necessary for the center to function successfully. Changes, whether in the way the QMaSC operates or improvements in facilities, are often made at the end of an assessment cycle when the assessment report and mission review provide the director with documented rationale for prospective change, the addition of resources, or the improvement in facilities.

\section{Annual Report}

An annual report is an ideal document to bring together all of the center's activities. A sequence of annual reports demonstrates to external reviewers evidence of the longitudinal accomplishments 
of the QMaSC. In addition, writing a summative report every year provides administrators and other interested parties with accurate information regarding QMaSC activities and services, and at the same time it helps the director to stay focused on fulfilling the QMaSC mission. Moreover, including the QMaSC staff in the preparation of the report or providing to them a version of the report educates them on the QMaSC's mission and how their work contributes to a wider set of goals. It is common for institutions to require that annual reports be written in a specific format, and, if so, the person to whom the QMaSC director reports can provide information regarding such a requirement. For those whose institutions have no required format, a suggested template is provided in Appendix D.

Directors who hesitate to perform the ambitious sort of assessment required for accreditation but still desire to craft an annual report may want to include some of the following information, when appropriate: the numbers of drop-in visitors and individual appointments with tutors; a list of center accomplishments and additional services such as workshops or special activities; populations served; and appropriate summaries regarding the learner satisfaction and the performance of the staff. When preparing an annual report, directors might want to refer to the associated chapters in this handbook on internal evaluation, reporting, and staff feedback.

\section{$7 \quad$ External Review Panels}

As mentioned in the introduction, not every review of a QMaSC is as extensive as that done by an accreditation body. Some institutions and QMaSC directors opt to have an external review of the QMaSC and its services conducted by an external team of experts. Often, these experts are directors or administrators of academic support centers from peer institutions. The QMaSC director may work with the institutional administration in identifying a list of potential candidates to serve on an external review panel. The director, or perhaps an academic dean or provost, will invite at least two, ideally three, candidates to serve on the review panel and establish a schedule of relevant meetings for the panel's campus visit. Once the panel is finalized, arrangements must be made for the transportation, lodging, and suitable compensation for the external reviewers.

The preparation of a self-study is a crucial element for such an external review. The selfstudy, assembled by the director, should contain materials similar in nature to the assessment documents described in detail for the accreditation body. In particular, the study should introduce the external review panel to the college and its mission; the QMaSC mission, objectives , services, and workshops; the most recent assessment of QMaSC services performed by the director; a frank appraisal of features and services when objectives are not met; a list of potential changes to meet those objectives; and ideas for expanding and enhancing services.

The self-study must be provided to the review panel prior to its arrival on campus. Once on campus, the review panel should meet with relevant faculty, QMaSC staff, students, and any other 
constituents who use QMaSC services. It is important that the panel's visit include considerable unscheduled time to allow for reflection. The panel needs time prior to meetings with relevant parties to discuss the study and to generate questions to ask of each constituency. Likewise, the review team needs a block of time after scheduled meetings to discuss their findings and to compose a report. In some cases, the report may be completed before the team members return to their home institutions. In other cases, the team may need time to devise a plan for compiling the report.

\section{Conclusion}

As stated at the outset, this chapter focuses primarily on compiling a full set of documents that may be required by an accreditation body. Most other audiences will not need to see such an extensive set of documentation, but it should be possible to construct a useful report to any external audience from this body of documents regardless of whether that external audience consists of institutional administrators or an outside review panel. Directors seeking additional resources regarding the main principles of effective communication about the services of their center, especially in the context of assessment results, may choose to refer to chapter 17 of [5].

\section{Bibliography}

[1] J. S. Eaton, "An overview of u. s. accreditation." http://www.chea.org/Research/index. asp\#overview, 2012. Internal document for Council of Higher Education.

[2] Southern Association of Colleges and Schools - Commission on Colleges, "Resource manual for the principles of accreditation: Foundations for quality enhancement." http://www.sacscoc. org/handbooks.asp, 2012.

[3] Western Association of Schools and Colleges, Accrediting Commission for Senior Colleges and Universities, "Assessment rubrics." http://www.wascsenior.org/document-list.

[4] B. E. Walvoord, Assessment Clear and Simple: A Practical Guide for Institutions, Departments, and General Education. Jossey-Bass, 2nd edition ed., 2010.

[5] L. Suskie, Assessing Student Learning: a common sense guide. Jossey-Bass, 2nd edition ed., 2009.

[6] "Academic program assessment workshop." Internal document of Southern Association of Colleges and Schools, 2012. 


\section{Acknowledgements}

Rachel Dunwell is very grateful for considerable assistance she received from Associate Dean Anita Davis, the Accreditation Liaison for Rhodes College, in the preparation of this chapter. 


\section{Appendix A}

Table 1: List of Accreditation Bodies and Associations

\begin{tabular}{|c|c|c|c|}
\hline Name & Full Title & Home Address & States \\
\hline MSA & $\begin{array}{l}\text { Middle States } \\
\text { Association of } \\
\text { Colleges and } \\
\text { Schools }\end{array}$ & http://www.msche.org/ & $\begin{array}{c}\text { New York, New Jersey, } \\
\text { Pennsylvania, Delaware, } \\
\text { Maryland, the District of } \\
\text { Columbia, Puerto Rico, and } \\
\text { the US Virgin Islands }\end{array}$ \\
\hline NEASC & $\begin{array}{l}\text { New England } \\
\text { Association of } \\
\text { Schools and } \\
\text { Colleges }\end{array}$ & http://cihe.neasc.org/ & $\begin{array}{c}\text { Connecticut, Maine, } \\
\text { Massachusetts, New } \\
\text { Hampshire, Rhode Island, } \\
\text { and Vermont }\end{array}$ \\
\hline $\mathrm{NCA}$ & $\begin{array}{l}\text { North Central } \\
\text { Association of } \\
\text { Colleges and } \\
\text { Schools }\end{array}$ & http://www.ncahlc.org/ & $\begin{array}{l}\text { Arkansas, Arizona, Colorado, } \\
\text { Iowa, Illinois, Indiana, } \\
\text { Kansas, Michigan, } \\
\text { Minnesota, Missouri, North } \\
\text { Dakota, Nebraska, New } \\
\text { Mexico,Ohio, Oklahoma, } \\
\text { South Dakota, Wisconsin, } \\
\text { West Virginia, and Wyoming }\end{array}$ \\
\hline NWCCU & $\begin{array}{c}\text { Northwest } \\
\text { Commission on } \\
\text { Colleges and } \\
\text { Universities }\end{array}$ & http://www.nwccu.org/ & $\begin{array}{c}\text { Alaska, Idaho, Montana, } \\
\text { Nevada, Oregon, Utah, and } \\
\text { Washington }\end{array}$ \\
\hline SACS & $\begin{array}{l}\text { Southern } \\
\text { Association of } \\
\text { Colleges and } \\
\text { Schools }\end{array}$ & http://www.sacscoc.org/ & $\begin{array}{l}\text { Virginia, Florida, Georgia, } \\
\text { Kentucky, Louisiana, } \\
\text { Mississippi, North Carolina, } \\
\text { South Carolina, Alabama, } \\
\text { Tennessee and Texas }\end{array}$ \\
\hline WASC & $\begin{array}{c}\text { Western } \\
\text { Association of } \\
\text { Schools and } \\
\text { Colleges }\end{array}$ & http://www.wascsenior.org/ & $\begin{array}{c}\text { California, Hawaii, Guam, } \\
\text { American Samoa, Micronesia, } \\
\text { Palau, and Northern } \\
\text { Marianas Islands }\end{array}$ \\
\hline CHEA & $\begin{array}{l}\text { Council for } \\
\text { Higher Education } \\
\text { Accreditation }\end{array}$ & http://www.chea.org/ & NA \\
\hline
\end{tabular}




\section{Appendix B}

Assessment Plan

Last Updated:

Organization: (name)

Mission Statement:

(description)

Table 2: Example Template for Assessment Plan

\begin{tabular}{|c|c|c|c|c|c|}
\hline Mission & $\begin{array}{c}\text { Link to } \\
\text { Institution's } \\
\text { Mission }\end{array}$ & Outcome & $\begin{array}{l}\text { Measurements } \\
\text { and Actions }\end{array}$ & $\begin{array}{c}\text { Responsible } \\
\text { Party }\end{array}$ & $\begin{array}{l}\text { Date/Freq } \\
\text { uency of } \\
\text { analysis }\end{array}$ \\
\hline $\begin{array}{l}\text { (portion of } \\
\text { own } \\
\text { Mission } \\
\text { supported) }\end{array}$ & $\begin{array}{l}\text { (Portion of } \\
\text { institution's } \\
\text { mission that is } \\
\text { supported) }\end{array}$ & (goal) & $\begin{array}{c}\text { 1. (means of } \\
\text { measuring) (area } \\
\text { of intended } \\
\text { action) } \\
\text { 2. (means of } \\
\text { measuring)(area } \\
\text { of intended } \\
\text { action) }\end{array}$ & $\begin{array}{l}\text { (who will } \\
\text { col- } \\
\text { lect/analyze } \\
\text { measure- } \\
\text { ments) }\end{array}$ & $\begin{array}{c}\text { (date last } \\
\text { measured/ } \\
\text { analyzed) } \\
\text { (next date } \\
\text { to } \\
\text { measure/an } \\
\text { alyze) }\end{array}$ \\
\hline & & & & & \\
\hline & & & & & \\
\hline & & & & & \\
\hline & & & & & \\
\hline
\end{tabular}

(Full descriptions of the measurement used should be given after the table, and cross-referenced to the appropriate row of the table.) 


\section{Appendix C: Example Template for Tracking Report}

An adaptation of the template found on page 32 of [6].

Goal. What goal did you assess? How does this goal support the mission?

Evidence. What assessment evidence did you collect? Where and how did you obtain the evidence? How many artifacts were collected and assessed?

Assessment Process. How did you assess the evidence? Include a copy of the rubric, if one is used. Who did the assessment? Describe any statistical analyses that you preformed. Describe how assessment findings and analysis were shared with interested parties.

Conclusions. What did you learn about the goal?

Closing the Loop. What actions did you take? Discuss consequences (including financial implications) of these changes.

Assess the Process. Did the data collection, analysis, and implementation of changes go well? What suggestions do you have for next time this goal is assessed? 


\section{Appendix D: Example template for Annual report}

Annual Report: Suggested Template for QMaSCs. (Adaptation of Template used by Rhodes College for Academic Departments)

This template organizes the report into three parts: an executive summary, a narrative section and four appendices.

Executive Summary: This should be a brief, one or two paragraph, summary of the document that follows.

Narrative :

- Services. Begin your narrative with a description of all the services that your Center provided for students using the Center, and an account of how widely the Center's services were used. Link these to the institution's curriculum, and other relevant areas of the institution's mission. Include descriptions of area of strength and weakness, with reference to supporting data, describing how the strengths can be maintained and weaknesses addressed. In the narrative consider the following questions:

- How many students used the various services that you offered? What proportion of students used the services? What proportion of the students made repeated use of services?

- How frequently all people working for the Center met and discuss the services provided? What was the focus of the discussion? Where any follow up actions taken?

- How frequently have you met with faculty to discuss how the Center's services support their teaching, and the learning outcomes of their students? What follow up actions were taken?

○ Where any new services offered this year? Did you change any of your procedures? Did these changes result in positive changes?

- What are the most significant challenges that the Center faces? How do you plan to address these challenges in the coming year?

- Are then any new services, or changes of procedure that you plan to introduce in the coming year?

- Staff. Begin this narrative with a consideration of the people who work in the Center and their various roles. Follow this with a consideration of the following questions:

○ How effectively have you been able to staff the services? Is your current faculty staffing level sufficient to accommodate next year's projected needs?

○ Is the work load spread evening across the staff? Should differences that exist be addressed?

- How does working in the Center help students attain learning outcomes? How do these outcomes link with and support the institution's experiential learning curriculum?

- What do you consider the most significant challenges in regard to your Center's staff? How might these be addressed?

- Facilities (including space). Begin this section with a consideration of your current facilities and an account of how well those are (or are not) meeting your needs. What are the issues 
related to facilities that we should try to address as soon as possible, and what should we plan for in the near future (say five years)?

- Departmental Activities. Describe any activities that your department carried out during the year, including participation in workshops, collaborating with other learning support centers, holding seminars, etc.

- Additional Information. Provide any other information about your Center that you would like to bring to our attention.

Appendices: Organize your supporting documents into appendices as follows:

I. Appendix 1. Attach the following assessment documents as Appendix 1, with sub-sections 1A- 1D:

- Appendix 1A: Your department's current assessment plan, including your mission statement and goals.

- Appendix 1B: An account of how attaining all the goals will allow the Center to fulfill its mission.

- Appendix 1C: A schedule of services offered by the Center. This should indicate the maximum number of students who could utilize the service, and the number or proportion of students who did so.

- Appendix 1D: Activity Tracking forms for each goal measured during the past academic year.

II. Appendix 2. List all noteworthy faculty and staff accomplishments for the year. This should include any academic credit that students earned through their work for the Center, any successful application for funds that support the work of the Center, and any publications relating to activities of the Center.

III. Appendix 3. Attach a list of services provided by each staff member in the Center during the year. 